\title{
Feasibility Study of Marine Controlled-Source Electromagnetic for Gas Hydrate
}

\author{
Kazunobu YAMANE ${ }^{1}$, Tatsuo SAEKI ${ }^{2}$ and Takao INAMORI ${ }^{2}$ \\ ${ }^{1}$ Geothermal Energy Research \& Development Co., Ltd \\ ${ }^{2}$ Japan Oil, Gas and Metals National Corporation
}

\begin{abstract}
Marine controlled source electromagnetic method may be one of the most significant new technologies for hydrocarbon exploration. The promise for the technology lies in its ability to differentiate resistive, potentially oil-bearing intervals from surrounding, more conductive water-bearing units. The principle is the same as that used in well logging devices to identify hydrocarbon zones in well bores. The technique is not new but the capability to resolve relatively thin resistive intervals in the depth offers new promise to lower the risk through direct hydrocarbon indicators in conjunction with modern seismic methods.

In this paper, we discuss the capability of marine CSEM method towards gas hydrate exploration by numerical studies of 1-D modeling and 2.5-D inversion.
\end{abstract}

\section{INTRODUCTION}

Electromagnetic (EM) methods for oil and gas exploration have been used for many years. These methods include magnetotelluric (MT), marine magnetotelluric (MMT). Conventional EM methods have provided practical solutions over past decades to difficult geological problems for which seismic methods proved ineffective. Examples of these situations include sub-volcanic and sub-salt surveys. In MT-MMT, naturally occurring electric and magnetic fields are measured at surface as they pass through areas of interest.

The marine controlled source electromagnetic (CSEM) method, although superficially similar to MT, is different and uses an artificial electrical dipole energy source instead of recording passive earth energy. This improves the resolution of the method by about an order of magnitude and permits the identification of thin resistors in a background formation of low resistivity down to tens of meters rather than the hundreds of meters typical of passive MT-MMT resolution.

For many years, there was mostly an academic interest to studying the resistivity structure of oceanic crust and upper mantle using marine CSEM. Recently, the industry is trying to apply this technology to hydrocarbon explorations on the continents offshore. Thus, the main targets of hydrocarbon offshore EM explorations are relatively resistive petroleum (Edwards, 2005).

One of the objectives of this paper is a better understanding of gas hydrate spatial distribution and its content in seafloor sediments using marine
CSEM. Gas hydrates are a mixture of methane and water in solid state. They are widely spread along coastal sediments covering large portion of the entire ocean. The zones and the depth interval of their distribution are controlled by the temperature and pressure. Gas hydrates are stable in oceanic sediments over the first hundred meters below seabed in shelf zones. Usually, the amount of gas hydrates increases with the increase of distance from seafloor and gradually reaches at a certain maximum, and after that, due to the phase transition gas hydrates becomes unstable. This lower boundary can be defined rather accurately by means of seismic methods, while the upper smoother boundary is practically difficult to be determined by reflection seismic, which makes impossible to estimate the amount of gas hydrate by seismic methods alone. That may be done only by resorting to resistivity data, since hydrates, being in solid state, act similar to ice, i.e. they replace the sea water in sedimentary pores and increase considerably their resistivity.

\section{Outline of Marine CSEM}

The basic idea behind the use of marine CSEM for industrial exploration is to identify resistive layers in an otherwise conductive environment. The fundamental equipment required to conduct a marine CSEM survey consists of seafloor EM receivers (Figure.1) and an electric dipole transmitter (Figure.2). A horizontal electrical dipole is towed close to the seafloor inducing a low 
frequency, typically $0.1 \mathrm{~Hz}$, EM signal which can be recorded by stationary sea bottom receivers. As illustrated in Figure 3, sea bottom receivers acquire the EM responses as a combination of energy paths including signal transmission directly through seawater, reflection and refraction via the seawater-air boundary, refraction and reflection along the seafloor, and reflection and refraction via possible resistive layer in subsurface.

EM signals decay exponentially with distance (m) by $\delta=503 \times \sqrt{\frac{\rho}{f}}$ and $\rho$ and $f$ indicate resistivity (ohm-m) and frequency(Hz) respectively. The value is called skin depth and is about $870 \mathrm{~m}$ in seawater, 2,200m in $2 \mathrm{ohm}-\mathrm{m}$ sediment for a $0.1 \mathrm{~Hz}$ signal. EM signals are rapidly attenuated in seawater and seafloor sedimentary formation saturated with saline water, and these signal paths is going to dominate at near source-to-receiver offset. In resistive layers, such as hydrocarbon and gas hydrate filled reservoirs, the EM energy is guided along the layers.

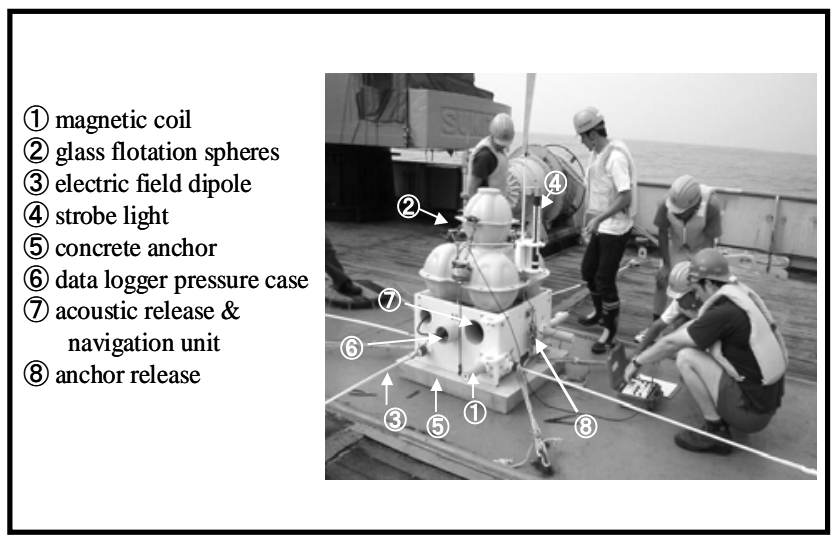

Figure 1 The receiver of Marine CSEM

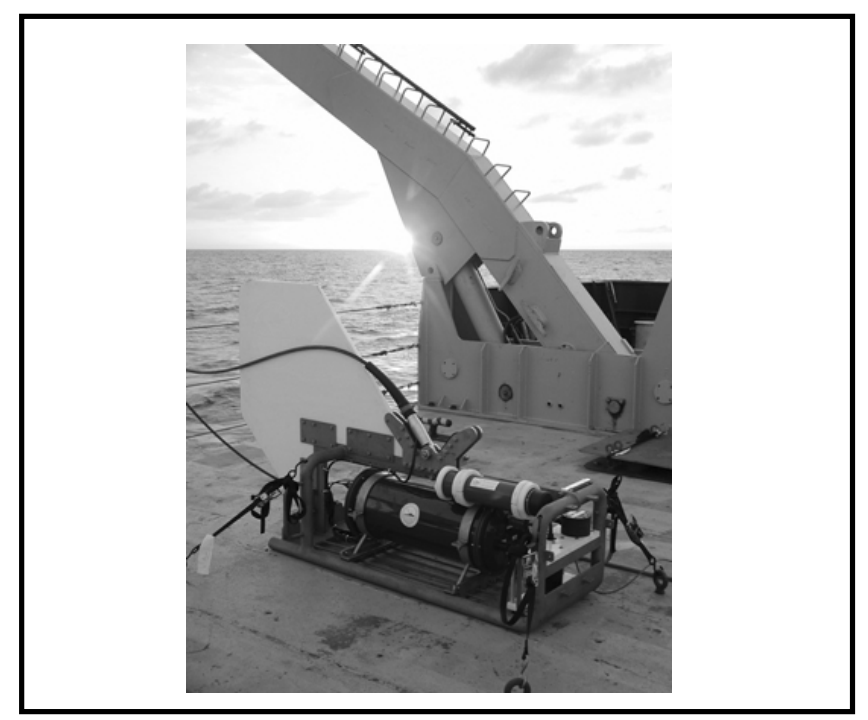

Figure 2 The transmitter of Marine CSEM (http://marineemlab.ucsd.edu/instruments.html )

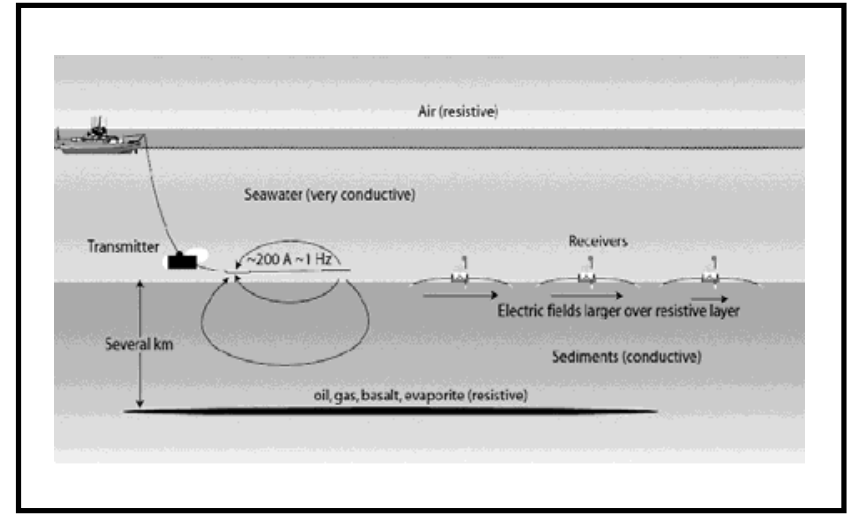

Figure 3. Survey configuration of marine CSEM (http://marineemlab.ucsd.edu/resources/presentatio ns/methods_talk.pdf)

\section{Numerical Studies}

\section{(1) 1-D Forward Studies}

To investigate how marine CSEM methods detect a thin resistive gas hydrate and what the factors governing their response are, synthetic electric fields (x-direction) for the gas hydrate and background models (homogeneous earth) are calculated using layered-earth (1-D) analytical code formulated by Dr. K. H. Lee (EM1D).

We constructed a series of layered models with a similar structure to the target area, Nankai Trough, as determined from induction resistivity logs in representative wells and reflection seismology in the area. All computations were made using a frequency of 1.0, 10.0 and $100.0 \mathrm{~Hz}$. However, the only result of $10 \mathrm{~Hz}$ is shown here. For each configuration, we show the field amplitude and phase with respect to source-receiver separations from $100 \mathrm{~m}$ to $3 \mathrm{~km}$.

The 1-D model (Figure 5) consists of 10 ohm-m layer representing gas hydrate, whose thickness is from $2 \mathrm{~m}$ to $10 \mathrm{~m}$, embedded at a depth $200 \mathrm{~m}$ below seafloor. A $2 \mathrm{~km}$ thick, $0.3 \mathrm{ohm}-\mathrm{m}$ seawater overlies the seafloor in the model.

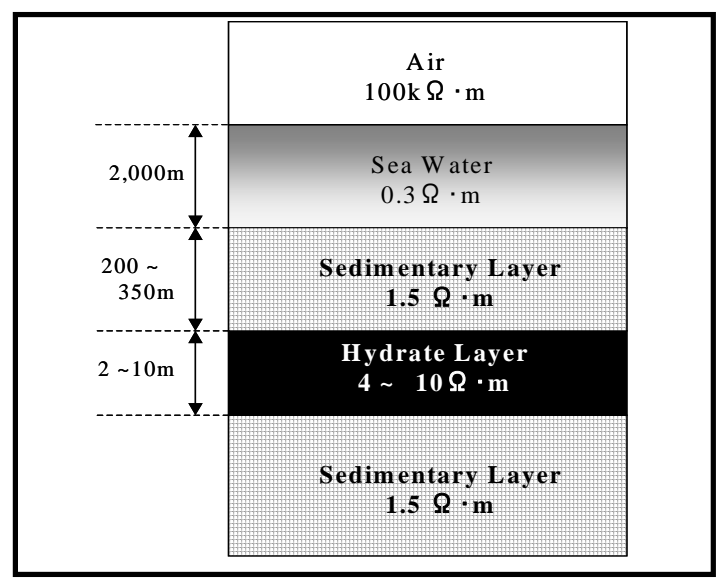

Figure 4 1-D Gas hydrate model 

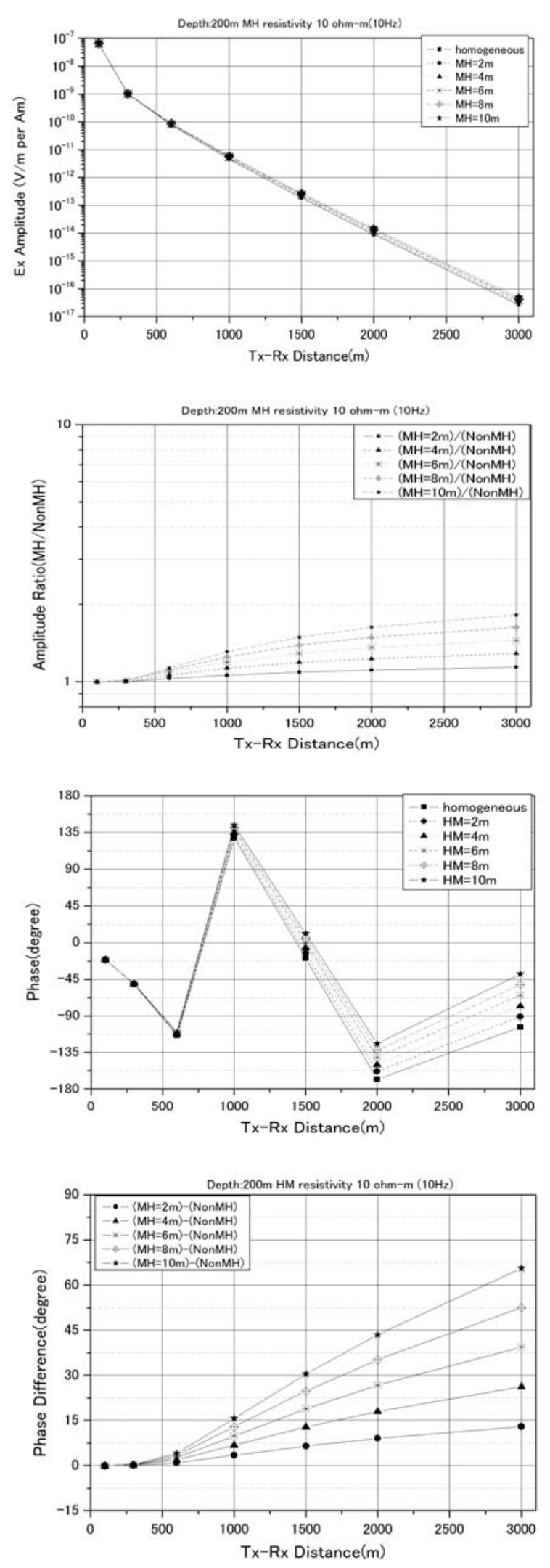

Figure 5. The 1-D response from gas hydrate with $10 \mathrm{ohm}-\mathrm{m}$. The thickness varies from $2 \mathrm{~m}$ to $10 \mathrm{~m}$.
As the background model (homogeneous earth), the same seafloor model is employed without gas hydrate. All result is calibrated by source moment and polarization. When we estimate the capability of marine CSEM by model response, we assume that the electric receiver noise level is to set $1.0 \mathrm{E}^{-14}(\mathrm{~V} / \mathrm{m}) \quad$ (Dr. S. Constable, personal communication). In other words, the amplitude below $1.0 \mathrm{E}^{-14}(\mathrm{~V} / \mathrm{m})$ should be neglected for our consideration in terms of the current EM receiver's performance.

Figure 5(a) shows the electric field amplitude (Ex) calculated at the seafloor for both the homogeneous and 1-D models with various thickness of hydrate layer. Figure $5(\mathrm{~b})$ is the normalized amplitude computed by dividing the 1-D responses by the homogeneous one.

Figure 5(c) is the phase value, and (d) is the phase difference provided by subtracting homogeneous value from 1-D hydrate models.

When the amplitude plot of Ex component for the background model is compared to that of the 1-D reservoir models (Figure 5(b), the amplitude ratio between hydrate models and non-hydrate model is less than 2.0, and it is nearly impossible to separate hydrate layer from the background. However, there are large differences between 1-D hydrate models and the homogeneous model in the phase difference (Figure 5(d)). As a result, the phase difference exceeds 20 degree for source-receiver separation distance about $2 \mathrm{~km}$ For the models with hydrate layers, it is easy to distinguish their existence using the phase data alone.

\section{(2) 2.5-D Inversion Studies}

Model to be consider here is a 2.5-D hydrate model consisting of $1.0 \mathrm{ohm}-\mathrm{m}$ marine sediment as background below $1 \mathrm{~km}$ thick sea water. The primary target is a thin $(10 \mathrm{~m})$ inclined gas hydrate with $7.0 \mathrm{ohm}-\mathrm{m}$ at the depth of $200 \mathrm{~m}$ from the sea floor. Frequencies used here are 0.5, 1 and $3 \mathrm{~Hz}$. Source type is $J x$, and the received component is Ex. The inversion started with a $1.0 \mathrm{ohm}-\mathrm{m}$ uniform sea sediment.

After 5 iterations, the cumulative RMS is 0.1 , and the results in resistivity image are shown graphically in Figure 6. The image of inclined body is smeared as shown in Figure 6. Thus, to estimate the gradient of anomaly through these inversion results is difficult. However, since the image shows the direction of inclination, the interpreter can infer that there exists an inclined anomalous body. 


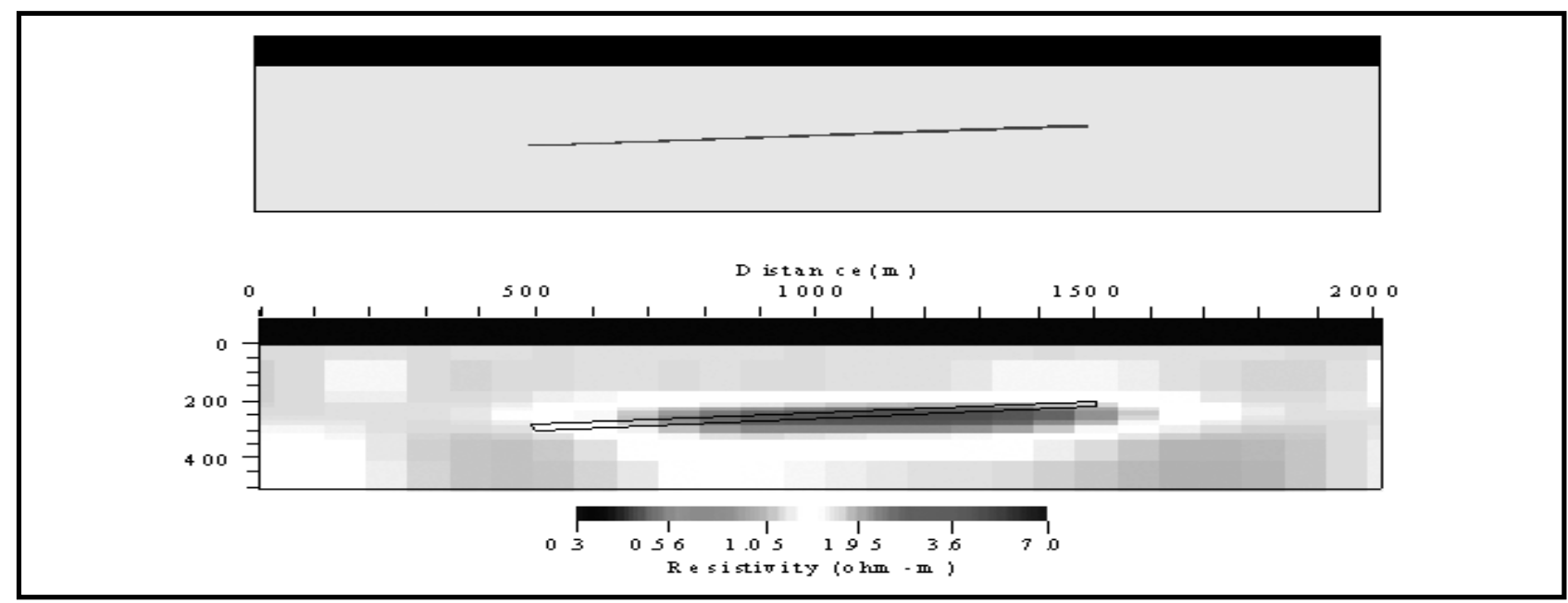

Figure 6 (Upper: Illustrations of inclined gas hydrate with $7 \mathrm{ohm}-\mathrm{m}$ is embedded, respectively, in conductive marine sediment. Lower : The reconstructed images after $5^{\text {th }}$ iteration)

\section{Case Study}

Marine CSMT survey was conducted by Scripps Institute of Oceanography at Hydrate Ridge, Oregon, the USA, in August, 2004. The detail of this experiment is described in Weitemeyer, K. A., et al (2006). 25 EM receivers were deployed with $600 \mathrm{~m}$ spacing in linear array. The electric current of $5 \mathrm{~Hz}$ was induced into seawater.

Hydrate Ridge (Figure 7), located about 85km offshore of the central Oregon margin, is one of the classic areas where the effects and processes associated with gas hydrate in near-seafloor sediment has been studied. The Ocean Drilling Program drilled Site 192 during Leg 146 on the northwest flank of Hydrate Ridge.

Figure 8 is the example of E-field amplitude at $5 \mathrm{~Hz}$ versus source-receiver offset. Third harmonic $(15 \mathrm{~Hz})$ is also processed, and used for inversion study.

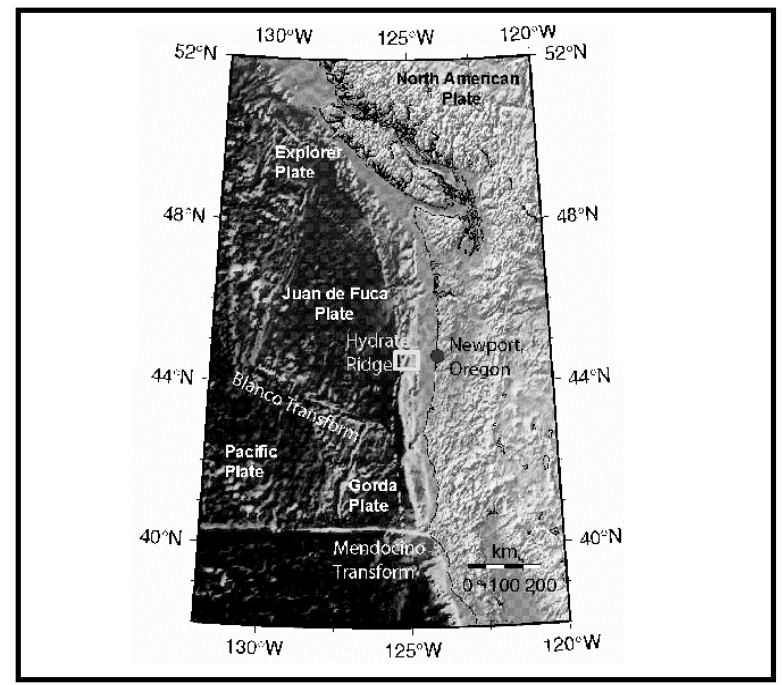

Figure 7 Bathymetry map of Hydrate Ridge (http://marineemlab.ucsd.edu/Projects/HYREX04 /index.html)

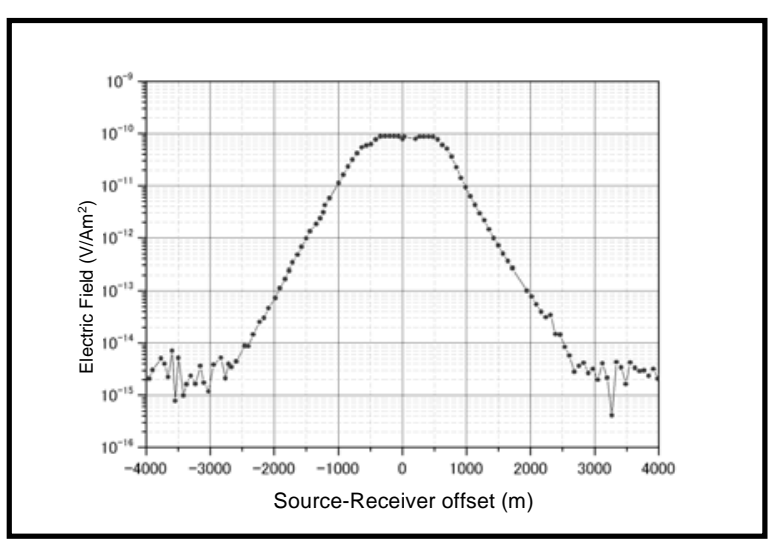

Figure 8 Example of E-field amplitude

\section{ACKNOWLEDGMENT:}

This research was conducted under the MH21 research consortium funded by Japan Ministry of Economy, Trade and Industry (METI). We wish to thank Japan Oil, Gas and Metals National Corporation (JOGMEC) for permission to publish this paper.

We also express our gratitude to Dr. Steve Constable of Scripps Institute of Oceanography for providing the opportunity of attending Oregon survey and scientific knowledge on marine CSEM. The authors also thank Dr. K. H. Lee for use of his code. We are very grateful to Dr. Arnold Orange of AOA geophysics, and Mr. Edwards Nichols of Schlumberger-EMI for illuminating discussions and technical assistance.

\section{REFERENCES}

Weitemeyer, K. A., Constable, S.C., Key, K. W., and Behrens, J. P., 2006, First results from a marine controlled-source electromagnetic survey to detect gas hydrates offshore Oregon, Geophysical Research Letters, 33, L03304 